\title{
GRAMMATIK
}

DER

\section{PORTUGIESISCHEN SPRACHE}

\author{
AUF GRUNDLAGE
}

DES LATEINISCHEN UND DER ROMANISCHEN SPRACHVERGLEICHING BEARBEITE'C

VoN

\section{D? CARL VON REINHARIDSTOETTNER.}

DOCENTEN DER ROMANISGHEN SPRACHEN UND IITTERATUREN AN DER KOENTGLICI TECUNISCILN HOCHSCHULE ZU MUENCIEN E'TC.

S'TRASSBURG.

K $\Lambda$ RL J. TRÜBNER.

LONDON.

TRÜBNER \& COMP. 1878. 
Buchdruekerei yon G. Ot to in Darmstadt. 